\title{
ANÁLISE DA COMPATIBILIDADE DA ESTRUTURA PRISIONAL PARA A REALIZAÇÃO DOS DIREITOS DAS MULHERES ENCARCERADAS
}

\author{
Ana Paula da Silva Sotero*1, Ruama Rosa Dionízio², Camila da Silva Sotero ${ }^{3}$ \\ and Luciano de Oliveira Souza Tourinho ${ }^{4}$
}

\begin{abstract}
${ }^{1}$ Advogada. Mestranda em Direito pela Universidade Federal da Bahia - UFBA. Especialista em Direito Penal e Processual Penal. Especialista em Criminologia. Graduada em Direito pela Universidade Estadual do Sudoeste da Bahia - UESB. Professora de Direito Penal da Faculdade Santo Agostinho de Vitória da Conquista; ${ }^{2}$ Discente do Curso de Arquitetura e Urbanismo da Faculdade Santo Agostinho de Vitória da Conquista; ${ }^{3}$ Engenheira Civil. Especialista em Engenharia das Estruturas. Professora de Engenharia Civil da Faculdade Santo Agostinho de Vitória da Conquista; ${ }^{4}$ Pós-doutor em Direitos Humanos (Direitos Sociais) pela Universidad de Salamanca. Doutor em Direito Público - Direito Penal pela Universidade Federal da Bahia. Mestre em Direito Público - Direito Penal pela Universidade Federal da Bahia. Especialista em Direito Público e em Ciências Criminais. Graduado em Direito pela Universidade Estadual do Sudoeste da Bahia. Professor Adjunto de Direito Penal e Direito Processual Penal na Universidade Estadual do Sudoeste da Bahia. Professor de Direito da Execução Penal na Faculdade Santo Agostinho de Vitória da Conquista. Coordenador do Programa de Pós-Graduação em Direito da Universidade Estadual do Sudoeste da Bahia. Diretor Geral da Faculdade Santo Agostinho de Itabuna
\end{abstract}

\section{ARTICLE INFO}

\section{Article History:}

Received $12^{\text {th }}$ February, 2021

Received in revised form

$03^{\text {rd }}$ March, 2021

Accepted $06^{\text {th }}$ April, 2021

Published online $22^{\text {th }}$ May, 2021

\section{Key Words:}

Estrutura Prisional; Mulheres encarceradas; Realidade Carcerária; Supressão de Direitos Humanos.

*Corresponding author: Ana Paula da Silva Sotero

\begin{abstract}
A realidade carcerária brasileira denota uma verdadeira supressão de direitos humanos, em que as condições de superlotação e de insalubridade das prisões tornam inviável a sobrevivência humana com dignidade, em especial das penitenciárias femininas. Dentro desse contexto, observa-se que a construção dos estabelecimentos penais foi pautada no dever do Estado de concretizar os direitos básicos e essenciais aos apenados, consoante os ditames do texto constitucional e da Lei $\mathrm{n}^{\circ} 7.210 / 84$, a Lei de Execução Penal. A partir desse paradigma entre as normas penais e a realidade do sistema prisional, o presente estudo tem por objetivo analisar a compatibilidade da estrutura arquitetônica prisional com a concretização dos direitos humanos para as mulheres encarceradas. Para delinear a presente proposta, este estudo analisou as condições estruturais físicas e arquitetônicas do Presídio Advogado Nilton Gonçalves, situado na cidade de Vitória da Conquista - BA, no intuito de avaliar as modificações estruturais necessárias nos presídios como políticas públicas de urgência para a concretização dos direitos humanos para as mulheres encarceradas. Para tanto, será utilizado uma orientação metodológica exploratória, com procedimentos técnicos bibliográficos de cultores da área de Direito Penal e da Arquitetura, bem como um estudo qualitativo da situação arquitetônica e estrutural do Presídio Advogado Nilton Gonçalves de Vitória da Conquista - BA.
\end{abstract}

Copyright (C) 2021, Ana Paula da Silva Sotero et al. This is an open access article distributed under the Creative Commons Attribution License, which permits unrestricted use, distribution, and reproduction in any medium, provided the original work is properly cited.

Citation: Ana Paula da Silva Sotero, Ruama Rosa Dionízio, Camila da Silva Sotero and Luciano de Oliveira Souza Tourinho, 2021. “Análise da compatibilidade da estrutura prisional para a realização dos direitos das mulheres encarceradas”, International Journal of Development Research, 11, (05), 47068-47072.

\section{INTRODUÇÃO}

A arquitetura prisional está intimamente ligada à própria história do surgimento da prisão e sua generalização como a única forma de punição adotada pela maioria dos países ao privar um indivíduo de liberdade em um determinado espaço governado por tempos de mudança. A arquitetura das prisões é essencial para o desenvolvimento das funções da pena e a garantia da resposta penal. Para isso, é necessário que as normas arquitetônicas das prisões estejam interligadas à legislação penal e ao cumprimento dos direitos humanos para que o espaço não seja visto como uma forma de punição do sujeito. Dentro do cenário histórico das prisões, superar o conceito de vingança e sofrimento das penas foi salutar e gradativo, tendo na histórica da construção arquitetônica de cada sociedade, as marcas do ideal de justiça criminal e de pena de cada população. Ocorre que a realidade carcerária brasileira não tem se distanciado das prisões antigas de vingança e punição, em que a arquitetura dos presídios acaba contribuindo para o falecimento das funções da pena e do descrédito do sistema criminal. As condições de superlotação, de insalubridade das celas e da ausência de concretização dos direitos humanos aos apenados denota a necessidade de repensar a estrutura 
arquitetônica das prisões para efetivar a justiça criminal e superar o paradigma punitivo repressivo que se delineia. No que concerne as mulheres encarceradas, objeto de estudo deste trabalho, a realidade carcerária feminina expõe variadas falhas arquitetônicas e a falta de planejamento das prisões que denotam a completa ausência de eficácia dos estabelecimentos prisionais femininos. Verifica-se que, apesar do avanço da legislação brasileira atinente às normas especiais para as penitenciárias femininas, em especial com a Lei $n^{\circ} 7.210 / 84$, que regula a execução penal no país, a realidade demonstra que o estado brasileiro ainda está longe de concretizar tais normativas especiais para as penitenciárias femininas. Para delinear a presente proposta, este estudo analisou as condições estruturais físicas e arquitetônicas do Presídio Advogado Nilton Gonçalves, situado na cidade de Vitória da Conquista - BA, no intuito de avaliar as modificações estruturais necessárias nos presídios como políticas públicas de urgência para a concretização dos direitos humanos para as mulheres encarceradas. Para tanto, será utilizado uma orientação metodológica exploratória, com procedimentos técnicos bibliográficos de cultores da área de Direito Penal e da Arquitetura, bem como um estudo qualitativo da situação arquitetônica e estrutural do Presídio Advogado Nilton Gonçalves de Vitória da Conquista BA.

\section{MATERIAIS E MÉTODOS}

A metodologia utilizada nesse estudo se caracteriza como uma revisão integrativa de literatura, tendo um caráter exploratório, e abordagem qualitativa dos dados coletados dos estabelecimentos prisionais femininos, em especial do Presídio Advogado Nilton Gonçalves. Para delinear a presente proposta, este estudo analisou as condições estruturais físicas e arquitetônicas do Presídio Advogado Nilton Gonçalves, situado na cidade de Vitória da Conquista - BA, no intuito de avaliar as modificações estruturais necessárias nos presídios como políticas públicas de urgência para a concretização dos direitos humanos para as mulheres encarceradas. Para tanto, será utilizado uma orientação metodológica exploratória, com procedimentos técnicos bibliográficos de cultores da área de Direito Penal e da Arquitetura, bem como um estudo qualitativo da situação arquitetônica e estrutural do Presídio Advogado Nilton Gonçalves de Vitória da Conquista - BA.

\section{RESULTADOS E DISCUSSÃO}

Arquitetura prisional: breve incursão teórica: Sabemos que entre as temáticas discutidas no âmbito brasileiro, que está trazendo preocupação e enfoque é a carcerária, que está ligada a estrutura pública, segurança pública e política criminal. A história das prisões denota a construção social de reprovação penal, que passou desde a representação da vingança para os povos primitivos até as prisões contemporâneas constitucionalizadas e amparadas pelo cumprimento dos direitos humanos. Partimos de um paradoxo que vem trazendo a atenção da população e da gestão para as condições e a dramática situação do sistema prisional com relação a parte estrutural, levando em conta a falta de espaços desqualificados, até mesmo para condições mínimas de atendimento a sociedade carcerária. A questão prisional concretiza o pressuposto de um compromisso com a eficácia das respostas criminais do nosso país, esta é sem dúvida uma das ferramentas para lidar e responder aos fenômenos criminais, sejam eles violentos ou de inegável impacto social. Segundo Beccaria (2002), a história das prisões coaduna com a própria história das civilizações antigas, em que a pena era vista como um meio de punição daquele que transgredia às normas de convivência. Segundo salienta o referido autor (2002), as prisões eram vistas como instrumentos de poder para marcar o corpo humano e puni-lo pelo mau praticado na sociedade. Insta consignar que a arquitetura prisional foi estabelecida depois das penas. Nas lições de Foucault (2005), a história das penas teve suas origens nos povos primitivos que buscavam garantir a ordem da comunidade, por meio de penas cruéis e de banimento do sujeito do convívio dos clãs. Nesse momento, não havia, portanto, uma estrutura prisional para $o$ cumprimento das penas, tendo em vista que o caráter punitivo era concentrado na expulsão ou na aflição do corpo. Nas lições de Bitencourt (2020), as penas vingativas eram privativas e tinham conotações divinas. Quando o indivíduo transgredia as ordens do seu clã, ele estava também transgredindo a ordem com seus próprios deuses. Nesse diapasão, a pena era um castigo divino que poderia ser resolvida de forma individual, pela ação e reação daquele que se sentiu injustiçado, valendo-se das Leis de Talião, em que a vítima injustiçada poderia fazer com o sujeito transgressor o mesmo mal praticado por ele. Segundo aduz Oliveira (2003), as Leis de Talião representam a primeira expressão de justiça criminal, mesmo que de forma primitiva, tendo em vista que para aplicar a punição faria uma análise proporcional do ato praticado. No entanto, não se pode descaracterizar o caráter aflitivo da punição, que iria desde a castração, ao flagelo dos corpos, as amputações até à morte. Com o avanço histórico das sociedades, os clãs e organizações primitivas foram construindo as civilizações que tinham interferência das culturas divinas que os povos cultuavam.

A partir desse momento, foram instituídos os Códigos de Hamurabi, as Leis Mosaicas e o Código de Manu, que traziam na pena também o efeito divino. Deveria se punir o corpo para se livrar a alma do sujeito. A incorporação dessas penas foi verificada no Egito, na Grécia Antiga e em Roma, com a construção dos seus impérios territoriais. Segundo Oliveira (2003), as penas assumiram o seu caráter mais cruel, sendo a aflição o elemento de destaque de punição do sujeito. Com a interferência da igreja, as penas passaram a ser verdadeiros suplícios, em que o indivíduo morria sob a prática de tortura. Beccaria (2002) denota que a morte era, então, a parte mais desejável de quem estava condenado a morrer com suplícios, pois o processo era de dor e sofrimento dilacerado. Nas lições de Bitencourt (2020), nesse período romano e da Idade Média, os suplícios passaram a serem aplicados em praças públicas, perfazendo a política de pão e circo, como verdadeiros espetáculos de sofrimento da condição humana. Foucault (2005) estabelece que as prisões começaram a ser introduzidas como celas de espera pelo momento do suplício público, com as execuções em praças, em que se praticava técnicas cruéis e de subjugação do indivíduo. No período renascentista do século XVIII, as penas cruéis e degradantes passaram a ser questionadas, momento em que Beccaria (2002) escreve sua obra Dos Delitos e Das Penas, a fim de oportunizar o debate sobre a necessidade de penas necessárias e suficientes para a reprovação do delito, sem crueldade. O direito criminal passa a ser instaurado por um processo de justiça com julgamento imparcial e reduzindo as penas de morte por penas de reparação e restituição da coisa, objeto do crime.

Na visão de Foucault (2005), as penas de morte passaram a ser substituídas por prisões perpétuas, em um sistema de castigo da alma, por meio de condições de sobrevivência nas masmorras subterrâneas e de vigilância contínua. Segundo salienta Beccaria (2002), as primeiras prisões começam a surgir a partir do século XVI, com a prisão canônica da igreja para punir os seus monges. Foram criadas celas nos mosteiros isoladas, em que o castigo dos monges era o recolhimento absoluto e a penitência com orações. Conforme estabelece Foucault (2005), as figuras arquitetônicas das prisões ganham contorno com a criação de celas de correção para mendigos e prostitutas na sociedade feudal. Com o êxodo rural e a vulnerabilidade de povos em decorrência dos grandes latifúndios de terra, as prisões eram vistas como forma de segregação espacial daqueles que viviam à margem da vida social. Ademais, as prisões também serviam para separar da sociedade todos aqueles que tinham comportamento imoral para a coletividade. Nota-se, nesse sentido, que a reprovação imoral não se perfazia por cometimento de crime e não submetia o indivíduo a um processo penal, mas apenas por sua conduta o sujeito já era deslocado para a prisão. Nas lições de Cordeiro (2009), a arquitetura das prisões de segregação era configurada como celas individualizadas e afastadas do convívio social, colocadas em locais subterrâneos para que não pudesse se escutar as aflições que as pessoas passavam naqueles locais. Conforme salienta a referida autora (2009), no século XVII surgiu outra configuração arquitetônica de prisão denominada de casa de 
correção para abrigar aqueles que praticavam crimes patrimoniais nas cidades e para abrigar as mulheres que se rebelavam contra às ordens de seus maridos, em decorrência da sociedade patriarcal. Após o período renascentista do século XVIII, a arquitetura prisional foi repensada a partir da construção de um sistema penitenciário pautado na humanização das penas e na substituição dos suplícios pelas penas privativas de liberdade. Nessa conjuntura, a arquitetura assume o papel de humanizar a prisão, retirando o caráter de punição e atribuindo apenas a função de reprovação pelos delitos praticados. Os primeiros modelos de sistemas prisionais foram pensados por Howard, na Inglaterra, ainda no século XVIII. Segundo Cordeiro (2009), Howard pensou a mudança da prisão a partir de sua própria experiência quando foi capturado por piratas. Desde então, dedicouse a planejar e desenhar projetos arquitetônicos da prisão ideal, salientando que as celas deveriam ser arejadas, em um recolhimento celular com possibilidade de trabalho diário e prática da religião para disciplinar o indivíduo.

Outro modelo de sistema criminal foi proposto por Bentham (2008) ao estabelecer que a disciplina deve ser a base da aplicação das penas. $\mathrm{O}$ autor criou e desenhou o panóptico, em 1785, que consistia em uma penitenciária ideal. A arquitetura da prisão era circular, de modo que o observador central teria como ter acesso visível a todas as celas, tendo todos os presos sob o seu controle e constante vigilância. Nesse tipo de arquitetura, cada cela tinha duas janelas para permitir a aeração dos espaços e evitar a contaminação de doenças. Tal panóptico foi estudado por Foucault (2005), observando que a disciplina consiste na vigilância pela luz das janelas, em que cada passo poderia ser vigiado por quem estivesse na torre de controle. Os sistemas penitenciários que mais se destacaram foram o pensilvânico, auburniano e o sistema progressivo que passou a ser adotado pelos países para aplicação das penas privativas de liberdade. O sistema pensilvânico surgiu na Filadélfia e era conhecido por se utilizar do sistema celular de Bentham e Foucault, porém, conforme salienta Bitencourt (2020), o preso era recolhido em celas individuais e ficava isolado dos demais presos, sem direito à visita, ao trabalho. Segundo Leal (2001), o sistema pensilvânico foi adotado em 1790, na prisão de Walnut Street Jail, na cidade da Filadélfia nos Estados Unidos. Esse sistema ficou conhecido pelo endurecimento das regras, em que o sujeito ficava em completo isolamento e tinha apenas a possibilidade de fazer a leitura da Bíblia, acreditando que o indivíduo se arrependeria dos seus pecados. Em decorrência das críticas ao sistema pensivâlnico e a sua ineficácia para a readaptação social do indivíduo, foi criado o sistema aurburniano, em 1818, construído na cidade de Auburn, no estado de Nova Iorque, nos Estados Unidos. Conforme salienta Bitencourt (2020), esse sistema era menos rigoroso do que o pensilvânico e permitia o trabalho individual dos presos, em suas próprias celas, que eram projetadas para adaptar as atividades laborativas dentro da prisão. Depois do cumprimento de parte da pena, os indivíduos seriam colocados em trabalhos coletivos durante o período diurno, sendo projetado a arquitetura de espaços coletivos para o desempenho das atividades.

No sistema aurburniano, o isolamento era apenas no período noturno, em que o dormitório deveria ser individualizado. Porém, conforme aduz Leal (2001), esse sistema tinha como característica essencial o completo silêncio durante a realização das atividades laborativas, no período diurno, o que levou aos presos a se comunicarem por gestos e por sinais que até hoje se utilizam nas prisões. O sistema auburniano foi substituído pelo sistema progressivo que surgiu na Inglaterra e foi aperfeiçoado na Irlanda, no século XIX. Tal arquitetura prisional foi modificada para permitir que o preso progredisse de regime ao longo de sua pena, sendo estabelecido a extinção da punibilidade e retirando o caráter perpétuo das prisões. Segundo salienta Leal (2001), o preso cumpriria a sua pena em três estágios: no primeiro estágio, o preso ficaria completamente isolado, em uma arquitetura nos moldes do sistema celular; no segundo estágio, o preso sairia do isolamento como progressão e teria a oportunidade de realizar o trabalho coletivo no período diurno e durante a noite faria o isolamento, em uma arquitetura nos moldes do sistema aurburniano; no terceiro estágio, o preso estaria em livramento condicional, com a liberação do sujeito. Conforme salienta Bitencourt (2020), o sistema progressivo irlandês acrescentou mais uma fase do sistema progressivo inglês, permitindo a construção de prisões intermediárias, com disciplinas leves, para preparar o sujeito para a vida em liberdade. Tal estágio foi inserido entre o estágio de trabalho coletivo e o livramento condicional. A partir da análise da arquitetura prisional, destacamos que no direito brasileiro foi adotado o sistema progressivo, instituindo o regime fechado, regime aberto e regime semiaberto, conforme artigo 59, inciso II, do Código Penal. Segundo a literatura do Código Penal, o regime fechado é formado pela arquitetura prisional das penitenciárias de segurança máxima, de celas individualizadas, mas com a garantia de todos os direitos constitucionais ao preso, não se estabelecendo o isolamento completo, conforme artigo 88 da Lei $n^{\circ}$ $7.210 / 84$. No regime semiaberto, a execução da pena se dá em colônias agrícolas ou industriais, projetadas para o trabalho coletivo dentro do estabelecimento penal. Além disso, as celas são coletivas, observadas as capacidades máximas planejadas no projeto estrutural do presídio, conforme enuncia o artigo 92 da Lei ${ }^{\circ} 7.210 / 84$. Já o regime aberto é cumprido na casa do albergado, situado em prédio urbano, sem obstáculos de fuga, a fim de testar a disciplina do preso que já está no último estágio de sua pena, conforme artigo 93 da Lei $\mathrm{n}^{\mathrm{o}} 7.210 / 84$. Segundo o artigo 41 da Lei $\mathrm{n}^{\circ} 7.210 / 84$, o preso tem direito à visita, ao trabalho, ao lazer e direito à vida digna enquanto cumpre pena em qualquer dos regimes iniciais de cumprimento de pena no país, devendo a arquitetura dos presídios projetarem instalações adequadas para o cumprimento dos direitos humanos aos aprisionados, com celas arejadas, locais de ventilação, estrutura para realização do trabalho, celas individualizadas para o recolhimento noturno, espaços de lazer, refeitório para alimentação de qualidade, espaço para assistência médica. Destaca-se, portanto, a importância da arquitetura como instrumento de garantia dos direitos humanos aos presos e do cumprimento das normas prisionais estabelecidas no Código Penal e na Lei de Execução Penal, a partir do planejamento e desenvolvimento de estabelecimentos penais capazes de garantir as funções de reprovação e ressocialização da pena.

A situação carcerária brasileira e os entraves arquitetônicos para garantia da realização dos direitos das presas femininas: $O$ sistema carcerário brasileiro está pautado no cumprimento das funções da pena de ressocialização e reprovação penal, que são elencados no artigo 59 do Código Penal. Por esse aspecto, a execução penal deve garantir que os apenados cumpram penas necessárias e suficientes para a reprovação do delito, mas também deve direcionar medidas de reinserção do sujeito no convívio da sociedade. Além disso, o ordenamento jurídico brasileiro é consubstanciado pelo respeito aos direitos humanos e fundamentais previstos na Constituição da República Federativa do Brasil de 1988. Por essa linha de intelecção, o Direito Penal não pode ser diferente e o sistema carcerário brasileiro está pautado nas garantias fundamentais elencadas no art. $5^{\circ}$ e $6^{\circ}$ da Constituição da República, estabelecendo os princípios constitucionais como instrumentos de modulação de todo o ordenamento. Dentro desses princípios constitucionais podemos destacar o princípio da igualdade de direitos e a isonomia formal, reproduzidos na lei penal e na lei de execução penal, devendo o Estado ser o garantidor da igualdade de direitos e garantias para os apenados, sem distinção de qualquer natureza, conforme art. $5^{\circ}$, caput da Magna Carta de 1988. Além disso, é assegurado aos presos o cumprimento de pena em estabelecimentos penais adequados e suficientes para garantir a integridade física e moral dos seres humanos, segundo enuncia o art. $5^{\circ}$, LXVIII, XLIX da Constituição da República de 1988.

Destaca-se ainda dos direitos e garantias fundamentais do apenado as vedações constitucionais de penas cruéis, de caráter perpétuo, trabalho forçado e de banimento do sujeito dentro do Estado Democrático de Direito, conforme estabelece o art. $5^{\circ}$, XLVII da Constituição da República de 1988, tendo como finalidade a concretização da dignidade da pessoa humana. O princípio da dignidade pessoa humana centralizou a construção da norma jurídica para a proteção da vida dos indivíduos, sendo dever do Estado garantir as condições mínimas de sobrevivência dos cidadãos, conforme preleciona Nunes $(2002,45)$ que "a dignidade é o primeiro fundamento de todo o sistema constitucional posto e o último 
arcabouço da guarida dos direitos individuais". Nessa mesma linha de intelecção, Santos $(2014$, p. 56) afirma que "o direito essencial que deve ser observado e preservado em um Estado Democrático de Direito é a dignidade humana, uma vez que este princípio é uma qualidade integrante da condição humana". Nessa linha de intelecção, quando se analisa as normas de direito penal e de execução penal, percebemos que os princípios constitucionais se constituem como verdadeiros limitadores do Jus Puniendi do Estado, tendo por base o inciso XLIX, do art. $5^{\circ}$, que estabelece que "ninguém será submetido à tortura ou a tratamento desumano ou degradante". Do mesmo modo tem-se a Lei no 7.210 de 1984 - Lei de Execução Penal, que estabeleceu as diretrizes e os instrumentos para a execução das penas, bem como a organização dos estabelecimentos penais no Brasil. Tal instituto cumpre com os objetivos de aplicar os princípios constitucionais e estabelecer o princípio da humanização das penas, a fim de permitir a promoção das finalidades da pena de prevenção e ressocialização do apenado. Destaca-se no artigo $3^{\circ}$ da Lei de Execução Penal que: "Ao condenado e ao internado serão assegurados todos os direitos não atingidos pela sentença ou pela lei". Nesse sentido, os sentenciados à pena privativa de liberdade, por ocasião da execução da pena, devem ter assegurados todos os seus direitos fundamentais, salvo aqueles incompatíveis com a condição atual e específica.

A proteção da dignidade humana aos apenados é de preocupação internacional e encontra respaldo no protocolo "As Regras Mínimas da ONU para o Tratamento de Prisioneiros" da Organização das Nações Unidas - ONU, que assegura aos apenados, dentre outras garantias, a construção de instalações limpas, arejadas, salubres e adequadas para a sobrevivência humana e respeito ao mínimo existencial de cada ser humano. Ademais, os países signatários do referido protocolo também devem adequar as prisões para a promoção da higiene do local e garantir o acesso à saúde e à alimentação de forma plena. Tais normas internacionais da ONU foram adotadas no Brasil com a Resolução $n^{0} 14$, do Conselho Nacional de Política Criminal e Penitenciária, que criou as Regras Mínimas do Preso no país, que requer o cumprimento da assistência médica, farmacêutica, odontológica e psicológica aos apenados e que foram estatuídas no art. 41 da Lei de Execução Penal. No entanto, apesar de todo o avanço delineado para a inclusão das garantias dos direitos humanos para os apenados no bojo do sistema penal, a realidade carcerária brasileira evidencia a completa supressão dos direitos humanos e a ineficiência estatal de garantir as funções de prevenção e ressocialização dos apenados. Em um contexto de falência dos estabelecimentos penais, marcados pela superlotação e pelas condições insalubres de vida, o Direito Penal está fadado ao fracasso e ao retrocesso social. Nesse contexto, observa-se que as construções arquitetônicas e estruturais das prisões brasileiras são verdadeiros espaços de desconstrução de direitos, com insuficiência de espaço físico adequado e a ausência de condições de vida de qualidade para a sobrevivência humana. Os muros que constroem as prisões são revestidos de dor e torturas, que se propagam em massa provocados pela superlotação dos presídios e pela completa insuficiência estrutural para abrigar os presos.

Nesse sentido pondera Sica (2002) que a verdadeira crise do sistema carcerário brasileiro deixou de ser um critério ideológico normativo, mas concentra-se na ausência de manutenções das prisões, nas condições desumanas dos espaços prisionais e na superlotação dos presídios que denotam a verdadeira falência da realidade penal. No que se refere a realidade carcerária feminina, observa-se que as condições físicas das instalações prisionais precarizam a saúde humana das mulheres encarceradas e dificultam o cumprimento dos direitos humanos. Segundo a Lei de Execução Penal, no artigo 14, $\S 3^{\circ}$, as penitenciárias femininas devem ser pautadas por regime especial, com instalações adequadas e próprias. Segundo os dados do Departamento Penitenciário Nacional - Depen, por meio do Levantamento Nacional de Informações Penitenciárias - Infopen (2019), a população carcerária brasileira é de 773.151 pessoas, entre presos provisórios e presos sentenciados. Em relação aos dados da população carcerária feminina no país, a taxa de ocupação é de 36.929 pessoas. Apesar de não ser a maior parcela da população encarcerada, o aprisionamento feminino destaca-se pela fragilidade das prisões para a saúde feminina. Ademais, segundo os relatórios anuais do Infopen (2019), observa-se que a população carcerária feminina cresceu $698 \%$ dentro de 16 anos.

O Infopen (2019) atestou que, em 2000, a realidade carcerária feminina era de 5.601 mulheres. Já em 2019, esse número saltou para 36.929 mulheres. Tais dados refletem na precarização da saúde e da estrutura arquitetônica das penitenciárias femininas. Os presídios femininos não foram planejados para comportar a estrutura da realidade da mulher, mas foram adaptados a partir do aumento da necessidade das mulheres nas prisões. Observa-se dos dados do Infopen (2019) que do total de 1420 unidades prisionais do país, apenas 103 eram exclusivamente femininas, o que corresponde a 7\% das unidades. Ademais, das unidades prisionais, 239 são mistas, sendo, portanto, a maioria das prisões destinadas para $o$ encarceramento masculino. Nos estabelecimentos femininos, ainda segundo os dados do Infopen (2019), apenas 34\% possuem cela ou dormitório para gestantes. Em relação às unidades mistas esse dado cai para $6 \%$. Quanto à existência de berçário e centros de maternidade infantil, que são direitos estabelecidos na Lei 7.210/84, apenas $32 \%$ das unidades femininas possuem. Apesar da ausência das instalações femininas, cerca de $28 \%$ das mulheres presas possuem filhos. No mapeamento feito pelo Infopen em março de 2020, observou-se que do total de mulheres presas, cerca de 12.821 são mães de crianças de até 12 anos que deveriam estar sendo assistidas pelas instalações de gestantes e maternidade infantil. Ainda segundo os dados oficiais de mapeamento das prisões femininas brasileiras, o Infopen (2020) observou que há uma ineficiência do direito à saúde da mulher nas unidades prisionais, tendo em vista que há um déficit de assistência médica dentro das prisões em $58 \%$ das unidades. De outro lado, ainda observamos que foram identificadas 4.052 presas com doenças crônicas e doenças respiratórias, que necessitam de um acompanhamento médico efetivo.

O Presídio nilton gonçalves e a (in) compatibilidade da estrutura prisional feminina em vitória da conquista-ba: $O$ presídio Advogado Nilton Gonçalves é um edifício de prisão em operação na cidade de Vitória da Conquista - Bahia. O terreno escolhido no projeto arquitetônico do estabelecimento prisional está localizado na Rua vinte e quatro, número 13, pertencente ao Parque Conveima I, no bairro Patagônia II. Para compreender a ocupação legal do estabelecimento prisional foi estudado o Código de Obras de Vitória da Conquista, em que o terreno é reconhecido como ZR 4 e se enquadra no IN1.1, definido pelas instituições vinculadas à polícia militar e ao sistema penitenciário. Antes de observar as instalações do estabelecimento penal, faz-se necessário observar o entorno da região penitenciária, para compreensão do projeto arquitetônico e verificar as dificuldades da localidade para a definição dos fluxos e características sociais e visuais. Em verificação do entorno da área do presídio Advogado Nilton Gonçalves, observa-se que se trata de área urbana, mas com ineficiência de infraestrutura adequada para a população, sendo classificada como zona periférica. O presídio Nilton Gonçalves de Vitória da Conquista - BA foi implantado em 1993, com o intuito de ser uma unidade prisional masculina para presos provisórios e definitivos. No entanto, o estabelecimento prisional foi readaptado para ofertar a ala feminina de presas provisórias e sentenciadas da região sudoeste. No decurso do tempo, recebeu reestruturações para adaptar as circunstâncias de instalação devido as diversas lotações locais. Com base no site do Governo do estado da Bahia, a unidade possui capacidade para abrigar 750 presos, porém, atualmente, comporta 817. Para além do problema óbvio da superlotação, a prisão enfrenta óbice da edificação antiga e hoje com o desenvolvimento da cidade, acaba localizado dentro de um bairro residencial, fazendo uma fronteira direta com as ruas do bairro. Sendo o único presídio misto e o mais antigo de Vitória de Conquista cidade localizada no Estado da Bahia, que era o único complexo penitenciário e que a datar do segundo semestre de 2016, a cidade conta com um novo Conjunto Penal. Localizado a $10 \mathrm{~km}$ do município, o novo complexo é destinado apenas a homens lembrando que o projeto inicial estava firmado em ideias diferentes, prevendo, também, a custódia de mulheres. Então, o Governo do 
Estado da Bahia concluiu a construção dessa nova penitenciária em Vitória da Conquista, que infelizmente, trouxe deficiências e contradições no projeto, ou seja, diversificados conflitos entre departamentos, e mais uma vez observamos que a prioridade e o foco são na segurança e não na ressocialização remota. No presídio Nilton Gonçalves temos uma ala dedicada as mulheres, essa ala é o módulo 3. Segundo o Mapa da População Carcerária, realizado pela Secretaria de Administração Penitenciária e Ressocialização - SEAP (BAHIA, 2021), o NG não abrigava nesse período número algum de presas, mas sabe-se que no ano de 2017 , o quantitativo nesse período era de um total de 60 custodiadas, entre as quais 46 estavam no regime provisório, 5 no regime semiaberto e 9 em regime fechado. Todas essas mulheres são abrigadas no mesmo ambiente, sem cumprir qualquer norma e conduta correta de separação entre tipos de crimes e tipos de regimes.

Em relação ao lado feminino da Penitenciária Nilton Gonçalves, esta é uma adaptação baseada em necessidades específicas, pois a unidade mais próxima seria na cidade de Jequié / BA, então para poder sanar essa dificuldade que causaria um maior desgaste as presas temporárias e para tentar minimizar os danos familiares para as famílias e filhos de detentos que aguardam julgamento em Vitória da Conquista - BA, foi improvisado essa área para utilização feminina.

Vale ressaltar que no presídio encontram-se detidas presas e detidas sentenciadas que aguardam transferência para as unidades penitenciárias de Salvador - BA e Jequié - BA. Para a disposição feminina temos um pátio na ala feminina que conta com 5 celas, dispondo da capacidade para 4 detentas em cada, levando a um total de 20 vagas femininas. Porém duas celas, apresentam-se interditadas por motivos estruturais, o que leva, consequentemente, a superlotação dessas celas e falta de qualidade mínima de estrutura, de saúde e de conforto. Toda a situação mostra que o poder público ignora a dignidade pessoal dos presidiários, que vivem em várias celas sem quaisquer condições mínimas de preservação da sobrevivência do ser humano. Inserindo a vida humana, é possível perceber a completa omissão do país. Nessas condições, o direito penal tornou-se ainda mais cruel e desumano e os fatos provaram que o direito penal é mais doloroso e punitivo do que a pena imposta ao crime cometido pelo criminoso. Sabemos que a cidade, além de encarar diversos problemas como a superlotação e descaso com o atual complexo penitenciário em funcionamento, o presídio Advogado Nilton Goncalves, também sentiu a influência do novo presídio, e a ineficácia deste novo presídio não foi questionada.

Em análise do local, foi observado a ausência de diversificados espaços, não se tem um ambiente adequado para humanizar a vivência naquele determinado espaço, percebemos uma má conceituação arquitetônica, exemplo disso são os diversos óbices nos espaços, como as "janelas" das celas que não oportunizam ao apenado que tenha uma visão exterior, e isso gera diversos e variados comportamentos ociosos e agressivos, que são potencializados justamente pela falta de humanização do local; as celas são irrestritamente fechadas; o fluxo de prisioneiros acontece por corredores mofinos. Em relação aos dados do Infopen (2019), observa-se que o estabelecimento prisional Advogado Nilton Gonçalves possui apenas 1 sala de consultório médico, mas sem atendimento diário. Ademais, o presídio conta com 1 depósito de material de limpeza, que não comporta a necessidade feminina de saúde. Além disso, verificou-se que a unidade prisional feminina de Vitória da Conquista não possui sala de esterilização, cela de espera, cela de enfermaria, berçário, sala para gestantes e maternidade infantil, cela de observação, sanitário para pacientes. Em situação de urgência da saúde feminina, as presas precisam ser deslocadas para o hospital público da cidade, em razão da ausência de equipamentos e assistência médica suficiente dentro da prisão. Verifica-se, portanto, que a realidade carcerária do presídio Advogado Nilton Gonçalves, em Vitória da Conquista - BA denota a ausência de um projeto arquitetônico para comportar as mulheres encarceradas, sem as instalações necessárias para a efetividade dos direitos humanos das presas. A ala feminina foi improvisada e, em toda a edificação do presídio, há a insalubridade das celas, a superlotação das celas e a ausência de manutenção necessária para a adaptação efetiva do presídio para as mulheres encarceradas, revelando a urgência de reformulação das instalações arquitetônicas do presídio como instrumento de melhoria das condições atuais do presídio.

\section{CONCLUSÕES}

A partir do estudo da arquitetura prisional dos estabelecimentos prisionais femininos, tendo como enfoque o Presídio Advogado Nilton Gonçalves de Vitória da Conquista - BA, impende registrar a urgência de uma reformulação do projeto estrutural e arquitetônico das prisões brasileiras para dirimir os problemas do cárcere feminino e garantir a execução da pena com dignidade e respeito aos direitos humanos. É necessário discutir novas alternativas para aplicação da pena, como desenvolver um plano entre a prisão e a cidade. Tendo em vista que a construção do direito penal é um importante instrumento de reeducação de presidiários. Uma nova alternativa baseada no sistema cujo principal objetivo é restaurar a reabilitação de detidas, restaurando a dignidade mental, social e profissional das criminosas.

\section{REFERÊNCIAS}

BECCARIA, Cesare. Dos delitos e das penas. São Paulo: Martin Claret, 2002.

BITENCOURT, Cezar Roberto. Manual de direito penal: parte geral, volume 1. $7^{\mathrm{a}}$ ed. rev. e atual. São Paulo: Saraiva, 2020.

BRASIL. Código Penal de 1940. Disponível em: http://www.planalto.gov.br/ccivil 03/DecretoLei/Del2848.htm//. Acesso em 20 de junho de 2017.

BRASIL. Conselho Nacional de Justiça. Regras de Bangkok: Regras das Nações Unidas para o Tratamento de Mulheres Presas e Medidas Não Privativas de Liberdade para Mulheres Infratoras. Brasília: Conselho Nacional de Justiça, 2016a. Disponível em: $<$ http://bit.ly/regrasdebangkok>. Acesso em: 27 mar. 2021.

BRASIL. Constituição (1988). Constituição da República Federativa do Brasil. Brasília, DF, Senado, 2013.

BRASIL. Infopen - Levantamento Nacional de Informações Penitenciária. $2^{\mathrm{a}}$ edição. Brasília: Ministério da Justiça e Segurança Pública, 2019.

BRASIL. Lei $N^{o} 7210$ de 11 de Julho de 1984. Dispõe sobre a Execução Penal. Brasília, DF: Congresso Nacional, 1984.

CORDEIRO, Suzann. De perto e de dentro: A relação entre o indivíduo encarcerado e o espaço arquitetônico penitenciário a partir de lentes de aproximação. Maceió, EDUFAL, 2009.

FOUCAULT, Michel. Vigiar e punir: nascimento da prisão. 30. ed. Petrópolis: Vozes, 2005.

LEAL, César Barros. Prisão: Crepúsculo de uma Era. 2 ed. Belo Horizonte: Del Rey, 2001.

NUNES, Luiz Antônio Rizzato. O princípio constitucional da dignidade da pessoa humana. São Paulo: Saraiva, 2002.

OLIVEIRA, Odete Maria de. Prisão: um paradoxo social. 3. ed. Florianópolis: Editora da Universidade Federal de Santa Catarina, 2003.

SANTOS, Boaventura de Souza. O direito dos oprimidos. Coimbra: Editora Almedina, 2014.

SICA, Leonardo. Justiça restaurativa e mediação penal: o novo modelo de justiça criminal e de gestão do crime. Rio de Janeiro: Lumen Juris, 2007. 